\title{
Neurosteroid Transport in the Brain: Role of ABC and SLC Transporters
}

\author{
Markus Grube, Paul Hagen and Gabriele Jedlitschky* \\ Department of Pharmacology, Center of Drug Absorption and Transport, University Medicine Greifswald, \\ Greifswald, Germany
}

OPEN ACCESS

Edited by:

Tea Lanisnik Rizner,

University of Ljubljana, Slovenia

Reviewed by:

Rainer Rupprecht,

University of Regensburg, Germany

Michael Schumacher,

Institut National de la Santé et de la

Recherche Médicale (INSERM),

France

Bruno Stieger,

Universität Zürich, Switzerland

${ }^{*}$ Correspondence:

Gabriele Jedlitschky

jedlits@uni-greifswald.de

Specialty section:

This article was submitted to

Experimental Pharmacology and Drug Discovery,

a section of the journal

Frontiers in Pharmacology

Received: 28 November 2017

Accepted: 27 March 2018

Published: 11 April 2018

Citation:

Grube $M$, Hagen $P$ and Jedlitschky G (2018) Neurosteroid Transport in the Brain: Role of $A B C$

and SLC Transporters.

Front. Pharmacol. 9:354.

doi: 10.3389/fphar.2018.00354
Neurosteroids, comprising pregnane, androstane, and sulfated steroids can alter neuronal excitability through interaction with ligand-gated ion channels and other receptors and have therefore a therapeutic potential in several brain disorders. They can be formed in brain cells or are synthesized by an endocrine gland and reach the brain by penetrating the blood-brain barrier (BBB). Especially sulfated steroids such as pregnenolone sulfate (PregS) and dehydroepiandrosterone sulfate (DHEAS) depend on transporter proteins to cross membranes. In this review, we discuss the involvement of ATP-binding cassette (ABC)- and solute carrier (SLC)-type membrane proteins in the transport of these compounds at the BBB and in the choroid plexus (CP), but also in the secretion from neurons and glial cells. Among the ABC transporters, especially BCRP (ABCG2) and several MRP/ABCC subfamily members (MRP1, MRP4, MRP8) are expressed in the brain and known to efflux conjugated steroids. Furthermore, several SLC transporters have been shown to mediate cellular uptake of steroid sulfates. These include members of the OATP/SLCO subfamily, namely OATP1A2 and OATP2B1, as well as OAT3 (SLC22A3), which have been reported to be expressed at the BBB, in the $\mathrm{CP}$ and in part in neurons. Furthermore, a role of the organic solute transporter OST $\alpha$-OST $\beta$ (SLC51A/B) in brain DHEAS/PregS homeostasis has been proposed. This transporter was reported to be localized especially in steroidogenic cells of the cerebellum and hippocampus. To date, the impact of transporters on neurosteroid homeostasis is still poorly understood. Further insights are desirable also with regard to the therapeutic potential of these compounds.

Keywords: ATP-binding cassette transporters, blood-brain barrier, dehydroepiandrosterone, DHEAS, neuroactive steroids, pregnenolone sulfate, solute carriers

\section{INTRODUCTION}

Neurosteroids are cholesterol-derived compounds categorized in pregnane neurosteroids (e.g., allopregnanolone), androstane neurosteroids (e.g., androstanediol), and sulfated compounds [PregS and DHEAS] (Reddy, 2010). They can be synthesized in the central nervous system, or the compounds themselves or precursors can be taken up from the systemic circulation (Baulieu, 1997; Maninger et al., 2009). One of their main functions in the brain is to modulate

Abbreviations: ABC, ATP-binding cassette; BBB, blood-brain barrier; BCRP, breast cancer resistance protein; CP, choroid plexus; CSF, cerebrospinal fluid; DHEAS, dehydroepiandrosterone sulfate; $\mathrm{E}_{1}$-3-S, estrone-3-sulfate; GABA, $\gamma$-aminobutyric acid; MRP, multidrug resistance protein; NMDA, $N$-methyl-D-aspartate; OATP, organic anion transporting polypeptide; OST, organic solute transporter; PregS, pregnenolone sulfate; SULT, sulfotransferase; TRP, transient receptor potential. 
excitability by interaction with membrane receptors and ion channels (Reddy, 2010). Accordingly, a therapeutic potential of these compounds or synthetic analogs has been discussed for a variety of brain disorders (Reddy, 2010). Local steroid biosynthesis in rodent and human brain has been studied since 1990s (Baulieu, 1997). Expression of key enzymes (e.g., P450 sidechain cleavage enzyme, $\mathrm{P} 450 \mathrm{c} 17$ ) has been demonstrated in the principal neurons of several brain areas and in the microglia and astrocytes (reviewed in: Maninger et al., 2009; Hojo et al., 2011; Porcu et al., 2016). However, the relative contributions of the local synthesis and uptake from blood to CNS levels have still to be clarified and may vary between different neurosteroids. In contrast to the lipophilic unconjugated compounds, especially DHEAS and PregS do not diffuse across membranes at a sufficient rate due to their hydrophilic sulfate moiety. Therefore, this review focuses on DHEAS/PregS membrane transporters in the brain. Both compounds play important roles in age-related memory and learning. They can be formed from the non-sulfated precursors by SULTs with SULT2B1b as a major isoform in the human brain (Salman et al., 2011). The ratio of sulfated versus non-sulfated neurosteroids in the brain may be decisive, since sulfation can change the direction of the neuromodulating activity. While for example some non-sulfated neurosteroids such as allopregnanolone are potent positive modulators of GABA type A receptors (for review see Chisari et al., 2010; Reddy, 2010), DHEAS and PregS have been shown to antagonize the GABA effect on the $\mathrm{GABA}_{A}$ receptor (Seljeset et al., 2015) and to be potent allosteric agonists at NMDA receptors (Wu et al., 1991; Monnet et al., 1995). Furthermore, PregS has been shown to directly activate certain TRP channels (Harteneck, 2013).

\section{DHEAS AND PREGS LEVELS IN PLASMA, BRAIN, AND CEREBROSPINAL FLUID (CSF) IN HUMANS}

While the serum concentrations of the non-sulfated DHEA and pregnenolone are in the low $\mathrm{nM}$ range in men and women (Labrie et al., 1997; Kancheva et al., 2011), levels of DHEAS are much higher with a slight difference between men $(2.3-11.5 \mu \mathrm{M})$ and women $(1.6-6.2 \mu \mathrm{M})$. It should be noted that here total steroid concentrations were measured. Due to the high plasma protein binding (95\% for DHEAS; Wang and Bulbrook, 1969) the concentration of the unbound steroids is accordingly lower. Generally, hormone levels decrease with age, exhibiting a maximum in young men and women ( $~ 20$ years; Labrie et al., 1997). Total PregS serum levels in adolescence range between 40 and $140 \mathrm{nM}$, and increase during pregnancy and at birth (de Peretti and Mappus, 1983; Kancheva et al., 2011). In contrast to DHEAS and PregS serum levels, less information is available on their tissue concentrations in the brain and in the CSF. In the human brain, region-dependent PregS concentrations between 5 and $40 \mathrm{nmol} / \mathrm{kg}$ have been reported with the highest levels in the striatum and hypothalamus. DHEAS concentrations were detected in a similar range with the highest levels in the striatum and cerebellum (Weill-Engerer et al., 2002). The CSF concentrations of DHEAS and PregS were much lower compared to the respective serum levels [serum/CSF ratios: 584 (Preg-conjugates), 19849 (DHEA-conjugates); Kancheva et al., 2011]. These gradients are due to the fact that both compounds cannot cross the respective barriers by passive diffusion, but depend on selective uptake and efflux proteins. ABC- and solute carrier (SLC)-type transporters may not only be relevant for the transport at the BBB and the blood-CSF barrier in the $\mathrm{CP}$, but also for secretion of these compounds from neurons and glial cells (Figure 1).

\section{TRANSPORTERS THAT MAY PLAY A ROLE IN THE TRANSPORT OF NEUROSTEROIDS: ABC TRANSPORTERS}

ATP-binding cassette proteins can mediate a unidirectional primary active transport of a variety of compounds across membranes. Among the ABC transporters especially ABCG2, also known as the BCRP, and several ABCC/MRP subfamily members are known efflux pumps for conjugated steroids (Suzuki et al., 2003; Haimeur et al., 2004).

\section{BCRP/ABCG2}

BCRP/ABCG2 was initially identified as a non-P-glycoprotein and non-MRP-type resistance factor from drug-selected cell lines (Doyle et al., 1998; Miyake et al., 1999). Besides anti-cancer drugs like mitoxantrone, BCRP actively transports sulfated steroids such as $E_{1}-3-S$ and DHEAS, but not unconjugated or glucuronidated steroids (Imai et al., 2003; Grube et al., 2007). The $\mathrm{K}_{m}$ value for $\mathrm{E}_{1}-3-\mathrm{S}$ calculated in isolated membrane vesicles was in the low $\mu \mathrm{M}$ range (Table $\mathbf{1}$ ). In addition, androgens such as dihydrotestosterone (DHT) have been identified as BCRP substrates (Huss et al., 2005). In human brain microvessels, ABCG2/BCRP transcript (Cooray et al., 2002; Warren et al., 2009) and protein was detected as one of the most abundant ABC transporters (Shawahna et al., 2011). Immunohistochemistry showed it primarily localized at the apical (luminal) side of the endothelial cells (Cooray et al., 2002; Aronica et al., 2005; Warren et al., 2009). In addition, it was detected in the apical membrane of the CP epithelium (Roberts et al., 2008a). Hence, BCRP could be involved in limiting the penetration of peripheral DHEAS and other steroids into the brain or facilitating the elimination of brain-derived DHEAS into blood. The apical localization in the $\mathrm{CP}$, on the other hand, indicate that here BCRP is able to transport neurosteroids into the CSF.

\section{Members of the MRP/ABCC Family}

Anionic conjugates of lipophilic compounds are typical substrates for several members of the MRP family. As the founding member, MRP1 (ABCC1) was identified as second export pump conferring a multidrug resistance phenotype besides the MDR1/P-glycoprotein (ABCB1) (Cole et al., 1992). MRP1 was subsequently shown to preferentially transport amphiphilic anions, especially conjugates of lipophilic compounds with glutathione, glucuronate, or sulfate (Jedlitschky 
A

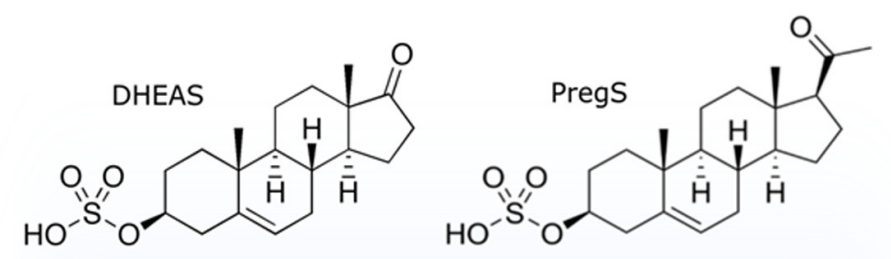

B
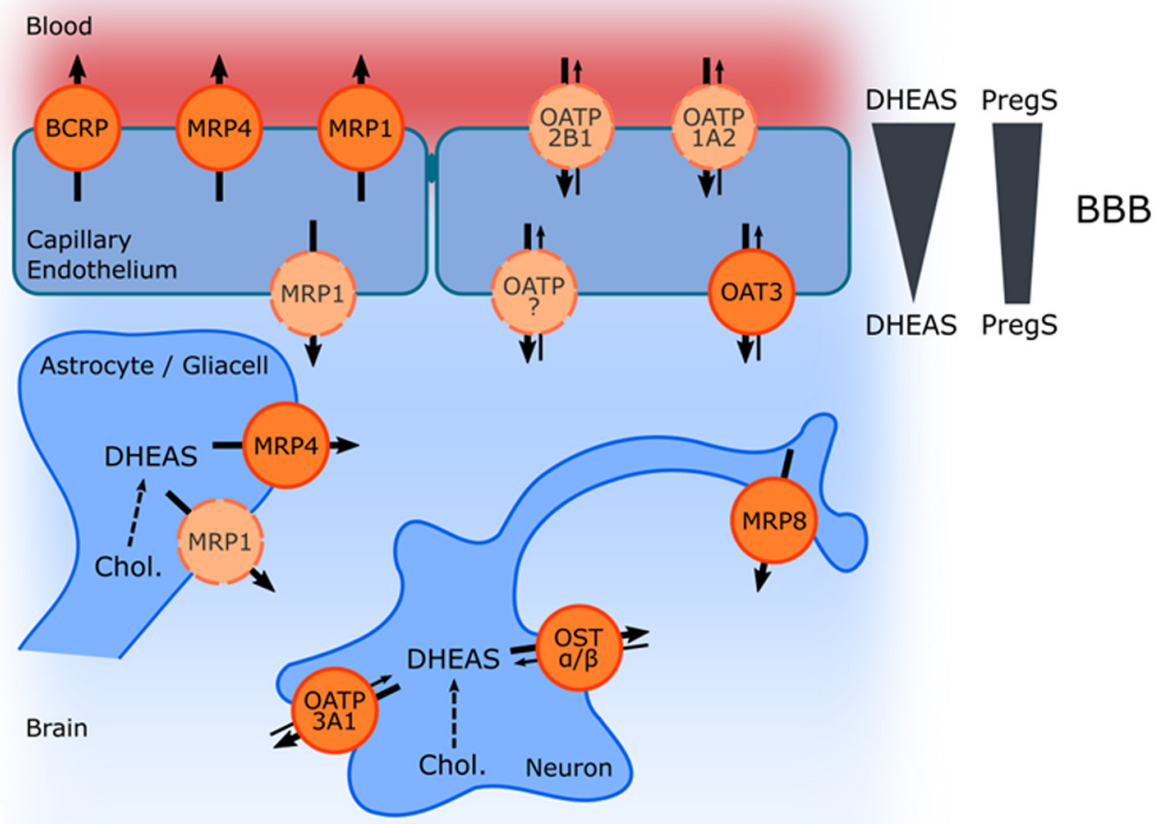

C

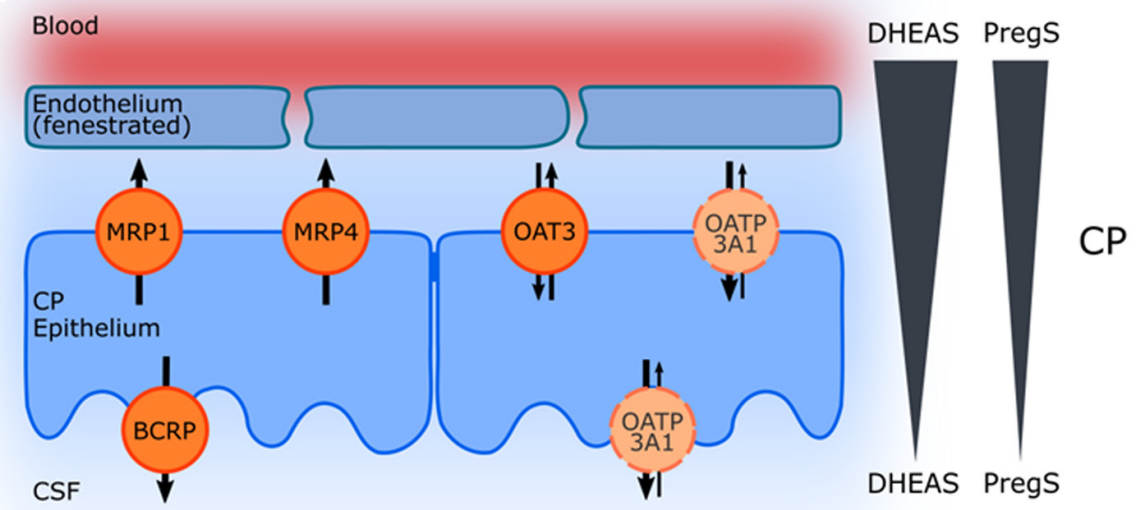

FIGURE 1 | Schematic illustration of ABC and SLC transporters putatively involved in DHEAS and PregS transport and their proposed localization. (A) Structures of DHEAS and PregS. (B,C) The ABC proteins BCRP (ABCG2), MRP1, MRP4, and MRP8 (ABCC1, ABCC4, and ABCC11), and the solute carriers OAT3 (SLC22A3), OATP1A2 (SLCO1A2), OATP2B1 (SLCO2B1), and OST $\alpha / B$ (SLC51A/B) may be involved in secretion of sulfated steroids from neurons and glial cells and/or in the transport across the BBB (B) as well as in transport at the blood-CSF barrier in the CP (C). The arrows indicate the directions of substrate transport. Proteins for which there is little or controversial evidence for expression and localization in the basal or apical membrane are indicated in light orange and by a dashed line. Concentration gradients of DHEAS and PregS across the BBB and in the CP are schematically indicated at the right side.

et al., 1996; Loe et al., 1996). MRP1 transports in addition certain cationic or uncharged compounds, but only in co-transport with reduced glutathione (GSH; Loe et al., 1996). It also mediates the transport of $E_{1}-3-S$ and of DHEAS in a glutathione-dependent manner (Qian et al., 2001; Zelcer et al., 2003) and is expressed in several tissues (Haimeur et al., 2004). It is also expressed in brain microvessels (Warren et al., 2009); however, the exact localization and function has not been finally clarified. It was detected to 
TABLE 1 | ABC and SLC transporters possibly involved in neurosteroid transport in the brain.

\begin{tabular}{|c|c|c|c|}
\hline Transporter & $\begin{array}{l}\text { CNS expression } \\
\text { (mRNA and protein analysis) }\end{array}$ & $\begin{array}{l}\text { CNS localization } \\
\text { (immunohistochemistry) }\end{array}$ & $\begin{array}{l}\text { Steroid substrates } \\
\left(K_{m} \text { value) }\right.\end{array}$ \\
\hline \multicolumn{4}{|l|}{ ABC Transporters } \\
\hline BCRP (ABCG2) & $\begin{array}{l}\text { mRNA: } \\
\text { - Total brain }{ }^{1} \\
\text { - Isolated brain microvessels }(\mathrm{BMV})^{2,3} \\
\text { Protein: } \\
\text { - BMV }(\mathrm{H}, \mathrm{M}, \mathrm{Mo}, \mathrm{R}, \mathrm{P})^{4,5,6,7,8} \\
\text { - Isolated } \mathrm{CP}^{9}\end{array}$ & $\begin{array}{l}\text { BBB: apical (luminal) }(H, R) \text {; } \\
\text { CP: apical }(H, R)^{2,10,11}\end{array}$ & $\begin{array}{l}\mathrm{E}_{1}-3-\mathrm{S}(6.8 \mu \mathrm{M})^{12,13} \\
\mathrm{DHEAS}^{12} \\
\mathrm{DHT}^{14}\end{array}$ \\
\hline MRP1 (ABCC1) & $\begin{array}{l}\text { mRNA: } \\
\text { - Total brain }{ }^{1} \\
\text { - } \text { BMV }^{3} \\
\text { - Isolated } \mathrm{CP}^{15} \\
\text { Protein: } \\
\text { - Isolated } \mathrm{CP}(\mathrm{H}, \mathrm{R})^{9,16}\end{array}$ & $\begin{array}{l}\text { BBB: apical }(H, B, M) \\
\text { Basal (abluminal) }(R, M) \\
\text { CP: basal }(H, R)^{17,18,19,20}\end{array}$ & $\begin{array}{l}\mathrm{E}_{1}-3-\mathrm{S}(+\mathrm{GSH})^{21} \\
\text { DHEAS }(+\mathrm{GSH})(5 \mu \mathrm{M})^{22} \\
\mathrm{E}_{2}-17 \beta \mathrm{G}(1.5 \mu \mathrm{M})^{23}\end{array}$ \\
\hline MRP4 (ABCC4) & $\begin{array}{l}\text { mRNA: } \\
\text { - Total brain }{ }^{1} \\
\text { - } \text { BMV }^{3} \\
\text { - Isolated } \mathrm{CP}^{15} \\
\text { Protein: } \\
\text { - BMV }(\mathrm{H}, \mathrm{M}, \mathrm{Mo}, \mathrm{R})^{4,5,6,7} \\
\text { - Isolated } \mathrm{CP}^{9}\end{array}$ & $\begin{array}{l}\text { BBB: apical }(H, M, R) \text {, } \\
\text { Apical + basal }(B) ; \\
\text { CP: basal }(H, R) ; \\
\text { Astrocytes }^{3,11,19,20,24}\end{array}$ & $\begin{array}{l}\text { DHEAS }(2 \mu \mathrm{M})^{22} \\
\mathrm{E}_{2}-17 \beta \mathrm{G}(30 \mu \mathrm{M})^{22,25}\end{array}$ \\
\hline MRP8 (ABCC11) & $\begin{array}{l}\text { mRNA: } \\
\text { - Total brain }{ }^{1}\end{array}$ & $\begin{array}{l}\text { Neurons (axonal; } \\
\text { cerebellum, cortex) }\end{array}$ & $\begin{array}{l}E_{1}-3-S(>150 \mu \mathrm{M})^{27} \\
\text { DHEAS }(13-21 \mu \mathrm{M})^{26,27} \\
E_{2}-17 \beta G(63 \mu \mathrm{M})^{27}\end{array}$ \\
\hline \multicolumn{4}{|l|}{ SLC Transporters } \\
\hline OATP1A2 (SLCO1A2) & $\begin{array}{l}\text { mRNA: } \\
\text { - Total brain }{ }^{1} \\
\text { Protein: } \\
\text { - BMV }(\mathrm{M}, \mathrm{Mo})^{5,6}\end{array}$ & $\begin{array}{l}\text { BBB: luminal; amacrine } \\
\text { neurons } 28,29,30,31\end{array}$ & $\begin{array}{l}\text { DHEAS }(7 \mu \mathrm{M})^{32} \\
\mathrm{E}_{1}-3-\mathrm{S}(16 \mu \mathrm{M})^{31}\end{array}$ \\
\hline OATP2B1 (SLCO2B1) & $\begin{array}{l}\text { mRNA: } \\
\text { - Total brain } 1 \\
\text { Protein: } \\
\text { - Brain capillary cells }{ }^{31}-\text { BMV }(M)^{6}\end{array}$ & $\begin{array}{l}\text { BBB: luminal; CP } \\
\text { (ependymal cells) (R); } \\
\text { amacrine neurons }{ }^{11,29,30,33}\end{array}$ & $\begin{array}{l}E_{1}-3-S(5-21 \mu M)^{34,35} \\
\text { DHEAS }(9 \mu M)^{35} \text { PregS }^{36}\end{array}$ \\
\hline OATP3A1 (SLCO3A1) & $\begin{array}{l}\text { mRNA: } \\
\text { - Total brain }{ }^{1} \\
\text { Protein: } \\
\text { - Isolated } \mathrm{CP}^{9} \\
\text { - BMV }(\mathrm{P})^{8}\end{array}$ & $\mathrm{CP} ;$ neurons $^{37}$ & $E_{1}-3-S^{38}$ \\
\hline OAT3 (SLC22A3) & $\begin{array}{l}\text { mRNA: } \\
\text { - Total brain }{ }^{1} \\
\text { Protein: } \\
\text { - Isolated CP9 } \\
\text { - BMV }(\mathrm{R})^{7}\end{array}$ & $\begin{array}{l}\text { BBB: basal }(R) \\
\text { CP: basal }(H, R)^{39,40,11,41}\end{array}$ & $\begin{array}{l}E_{1}-3-S(8.8 \mu M)^{42} \\
\text { DHEAS }^{42}\end{array}$ \\
\hline OST $\alpha$-OST $\beta$ (SLC51A/B) & & $\begin{array}{l}\text { Neurons (cerebellum, } \\
\text { Hippocampus; Purkinje cells) }\end{array}$ & $\begin{array}{l}\text { DHEAS }(1.5 \mu \mathrm{M})^{43} \\
\text { PregS }(6.9 \mu \mathrm{M})^{43}\end{array}$ \\
\hline
\end{tabular}

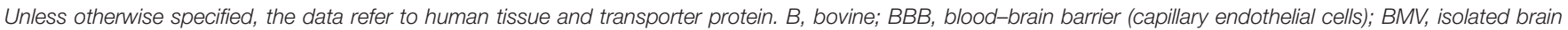

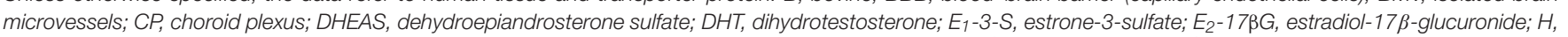

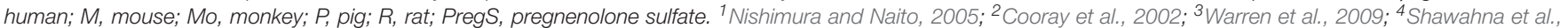

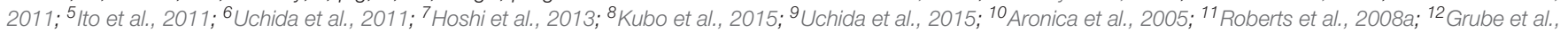

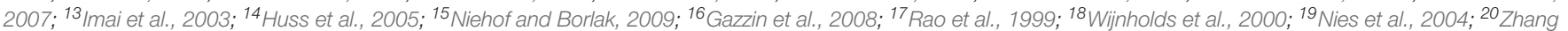

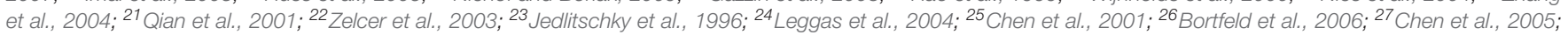

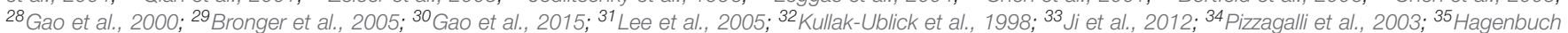

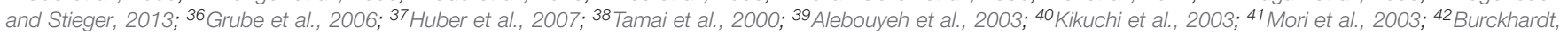
2012; ${ }^{43}$ Fang et al., 2010.

be luminal in humans, bovine, and murine brain (Nies et al., 2004; Zhang et al., 2004), but also localization at the basolateral (abluminal) membrane was described in mice and rats (Kilic et al., 2008; Roberts et al., 2008a). Some groups did not detect MRP1 protein in human brain capillaries at all (Rao et al., 1999; Aronica et al., 2005). Because of the inconsistent and low-level expression, the relevance of this transporter at the $\mathrm{BBB}$ is so far unclear. It may play a more important role in the CP. Here, MRP1 mRNA was detected in rat and human tissue (Gazzin et al., 2008; Niehof and Borlak, 2009) and the protein was localized at the basolateral membrane (Rao et al., 1999; Wijnholds et al., 2000; Gazzin et al., 2008). Thus, it may be involved in the efflux 
of conjugated steroids from the CSF into blood. In addition, MRP1 mRNA was detected in cultured rat and human astrocytes (Hirrlinger et al., 2001; Spiegl-Kreinecker et al., 2002). However, the protein could not been detected in human glial cells or neurons in immunohistochemical studies (Nies et al., 2004; Aronica et al., 2005). MRP1 and MRP2 (ABCC2) share a similar substrate spectrum, but MRP2 is mainly expressed in polarized epithelial cells (Keppler, 2011). Immunostaining at the apical membrane in brain capillaries was described in rats (Miller et al., 2000), but was not observed in human and bovine brain (Nies et al., 2004; Zhang et al., 2004). Similarly, MRP3 (ABCC3) protein was not detected in human brain (Nies et al., 2004).

A more relevant efflux transporter for conjugated steroids in the brain may be MRP4/ABCC4, which exhibits a unique broad substrate specificity. MRP4 shows the remarkable capacity to transport cyclic nucleotides and MRP4 has been established as an independent regulator of intracellular cAMP levels in several cell types (Ritter et al., 2005; Jedlitschky et al., 2012; Belleville-Rolland et al., 2016). Furthermore, MRP4 transports lipid mediators such as prostanoids and conjugated steroids. DHEAS is transported by MRP4 in a glutathione-independent manner and with high affinity $\left(\mathrm{K}_{m}\right.$ of $2 \mu \mathrm{M}$; Zelcer et al., 2003). It is expressed in several tissues especially in the prostate, kidney, blood cells, and brain (Kool et al., 1997; Haimeur et al., 2004; Nishimura and Naito, 2005; Niehof and Borlak, 2009; Warren et al., 2009; Shawahna et al., 2011). Here, it was localized apically in human, rodent and bovine capillaries (Nies et al., 2004; Leggas et al., 2004; Zhang et al., 2004; Roberts et al., 2008a). An additional detection at the basolateral membrane was only described in bovine brain (Zhang et al., 2004). MRP4 expression was also detected in human CP (Niehof and Borlak, 2009; Uchida et al., 2015) and it was localized to the basolateral membrane in human and murine tissue (Leggas et al., 2004). Moreover, it is expressed in glial cells. Immunofluorescence studies in the human brain revealed staining mainly in astrocytes of the subcortical white matter (Nies et al., 2004). Since glial cells are able to synthesize neurosteroids, MRP4 may account for the efflux of DHEAS and other neurosteroids from these cells for a paracrine action. Astrocytes play a critical role for the development and function of neurons and these cells in turn are regulated by steroid hormones as progesterone and DHEA (Acaz-Fonseca et al., 2016; Arbo et al., 2016). At the BBB and the CP, MRP4 may contribute to the transport of sulfated steroids from brain and CSF into blood.

A further member of the MRP family, the MRP8 (ABCC11) may be relevant with respect to neurosteroid transport. MRP8 was shown to transport DHEAS in isolated membrane vesicles with a $\mathrm{K}_{m}$ value of $13-21 \mu \mathrm{M}$, whereas the $\mathrm{K}_{m}$ was above $150 \mu \mathrm{M}$ for MRP8-mediated transport of $\mathrm{E}_{1}-3-\mathrm{S}$ (Chen et al., 2005; Bortfeld et al., 2006). In immunofluorescence studies, it was detected preferentially in the white matter of the cortex and cerebellum and co-localized with neurofilaments indicating localization in neuronal axons (Bortfeld et al., 2006). In addition, weak immunostaining was detected in the gray matter and also in the axons of peripheral neurons. The axonal localization implies that MRP8 can mediate presynaptic efflux of neurosteroids from neurons and thus could directly participate in modulating postsynaptic neurotransmitter receptors (Bortfeld et al., 2006).

\section{Uptake (SLC) Transporters}

Besides ABC-type efflux transporters, neurosteroid concentrations in the brain may also be modulated by uptake transporters. Since several members of the SLC superfamily have been identified as uptake transporters for steroid conjugates in general, these transporters are interesting candidates for the transport of neurosteroids. In fact, several SLCs have been shown to mediate cellular uptake of DHEAS and PregS.

\section{Members of the OATP/SLCO Family}

Among the SLC transporters, the OATP (SLCO) family is probably the most interesting one in this context. In humans, 11 SLCO transporters exist, organized in six families (Hagenbuch and Stieger, 2013). The physiological substrate profile of the OATP transporters comprises a wide variety of endogenous organic anions including bile acids, bilirubin, thyroid hormones, and prostaglandins (Hagenbuch and Stieger, 2013). In addition, OATPs transport steroid hormone conjugates like $\mathrm{E}_{1}-3-\mathrm{S}$ (nearly all OATPs) or estradiol-17 $\beta$-glucuronide (OATP1A2, OATP1B1, OATP1B3, OATP1C1, and OATP4A1) and the neurosteroid DHEAS (OATP1A2, OATP1B1, OATP1B3, and OATP2B1) (Hagenbuch and Stieger, 2013). The affinity of these transporters toward DHEAS was slightly above (OATP1B1 and OATP1B3) or in the range (OATP2B1 and OATP1A2) (Table 1) of the physiological plasma concentration (1.6-11.5 $\mu \mathrm{M}$; Labrie et al., 1997) indicating an in vivo relevance of these findings. OATP1B1 and OATP1B3 are almost exclusively expressed in the human liver. Here, they are responsible for cellular uptake as a prerequisite for hepatic metabolism and elimination. In turn, the expression and function of these transporters affect systemic DHEAS levels as shown by enhanced DHEAS levels in monkeys and rats after treatment with the unspecific OATP inhibitor rifampicin (Watanabe et al., 2015; Nishizawa et al., 2017). Assuming a DHEAS transport/uptake from the blood into the brain/CSF (Kancheva et al., 2010), changes in DHEAS plasma concentration might indirectly influence the concentration in these compartments. Therefore, OATPs localized in the BBB and/ or the CP are of special interest. Indeed, OATP1A2, OATP1C1, OATP2B1, and OATP3A1 have been detected in these structures in humans (Kullak-Ublick et al., 1998; Pizzagalli et al., 2002; Huber et al., 2007; Roberts et al., 2008b; Ji et al., 2012). Since OATP1C1 is a thyroid hormone transporter and the function of OATP3A4 is only poorly understood, at present OATP1A2 and OATP2B1 are probably the most interesting members concerning neurosteroid transport in the brain. Both proteins are expressed in the endothelial cells of the $\mathrm{BBB}$ presumably in the luminal membrane predisposing them as transporters for uptake into the brain (Gao et al., 2000; Bronger et al., 2005; Lee et al., 2005). In addition, OATP1A2 and OATP2B1 are also expressed in other CNS cell types. While both transporters have been identified in amacrine neurons of the retina, OATP1A2 was additionally found in hippocampal pyramidal and granule cells (Gao et al., 2015). Besides DHEAS, PregS levels in the brain may also be influenced by uptake transporters in the $\mathrm{BBB}$, even though plasma concentrations of PregS were up to two orders of magnitude below the 
DHEAS levels (Sanchez-Guijo et al., 2015). Like for DHEAS, OATP-transporters are interesting candidates in this context. While PregS significantly inhibits OATP2B1 function (St Pierre et al., 2002; Grube et al., 2006) first reports indicated no direct transport of PregS by this transporter (Pizzagalli et al., 2003; Grube et al., 2006). Interestingly, OATP2B1-mediated transport of $E_{1}-3-S$ and DHEAS was stimulated by steroid hormones like progesterone (Grube et al., 2006; Koenen et al., 2012). Under these conditions, PregS was also transported by OATP2B1 (Grube et al., 2006). PregS transport by other OATPs has not been studied so far. With regard to the $\mathrm{CP}$ only limited information is available about OATP expression and function in humans. In a recent LC-MS/MS-based study examining transporter protein expression in this structure, only OATP3A1 was detected, while OATP1A2 and OATP1C1 were below the detection limit and OATP2B1 was not analyzed (Ji et al., 2012). This finding was quite surprising, since in animal models several OATPs have been detected in the CP and shown to be involved in the neurosteroid transport into the liquor (Asaba et al., 2000; Choudhuri et al., 2003; Ji et al., 2012). Due to the limited information available, the significance of OATP3A1 in this context cannot be conclusively assessed. However, a transport of $E_{1}-3-S$ has also been shown for the OATP3A1 and two splice variants of the transporter are selectively expressed in the apical and basal membrane of the ependymal cells of the CP (Tamai et al., 2000; Huber et al., 2007).

\section{Other Organic Anion Transporters (OST $\alpha$-OST $\beta$, OATs)}

Besides OATPs, an interaction of neurosteroids (mainly DHEAS and PregS) with several further organic anion transporters has been reported. For example, both sulfated neurosteroids have been shown to be transported with high affinity by the organic solute transporter OST $\alpha$-OST $\beta\left[\mathrm{K}_{m}: 1.5 \mu \mathrm{M}\right.$ (DHEAS) and $6.9 \mu \mathrm{M}$ (PregS)] (Fang et al., 2010). The heterodimer OST $\alpha-O S T \beta$ is a relatively new member of the SLC family (SLC51) and encoded by two genes (SLC51A and SLC51B). Like OATPs, the transport mechanism is facilitated diffusion; therefore OST $\alpha$-OST $\beta$-mediated transport is dependent on the electrochemical gradient of its substrates (Ballatori et al., 2013). In the human brain, the transporter is expressed in Purkinje cells and hippocampal neurons (Fang et al., 2010). Both regions are well known for their function in the process of learning and memory, and hippocampal neurons have been suggested as a target site for PregS action (Akwa et al., 2001).

A third group of SLC transporters involved in the CNS distribution of sulfated neurosteroids are the organic anion transporters (OATs), which are part of the SLC22A branch (Burckhardt, 2012). The pivotal role of these transporters is the

\section{REFERENCES}

Acaz-Fonseca, E., Avila-Rodriguez, M., Garcia-Segura, L. M., and Barreto, G. E. (2016). Regulation of astroglia by gonadal steroid hormones under physiological and pathological conditions. Prog. Neurobiol. 144, 5-26. doi: 10.1016/j.pneurobio.2016. 06.002 excretion of water-soluble organic anions in the kidney. However, selected members are also present in other organs including the brain (Burckhardt, 2012). In the brain OAT3, is probably the most interesting member of this family. The transporter is expressed in the BBB as well as the CP (Alebouyeh et al., 2003; Kikuchi et al., 2003; Uchida et al., 2015). In a mouse model, OAT3 was characterized as the DHEAS transporter in part responsible for the DHEAS efflux across the BBB (Miyajima et al., 2011). Besides OAT3, mRNA expression of OAT1 and OAT2 has also been shown for the human brain (Lopez-Nieto et al., 1997; Alebouyeh et al., 2003; Cropp et al., 2008); however, protein data for these transporters are limited.

\section{CONCLUSION AND PERSPECTIVES}

The detailed functions of the described ABC and SLC transporters in brain are still poorly understood. Even data on the expression and localization, e.g., at the $\mathrm{BBB}$ are often controversial. Knock-out mice of the ABC and some SLC transporters are available, but have been mainly used to study the role of these transporters for brain penetration of certain drugs (Dallas et al., 2006; Chaves et al., 2014). These studies are in part hampered by overlapping substrate specificities of several transporters and with respect to neurosteroids by the fact of negligible levels of sulfated steroids in rodent brain (Liu et al., 2003; Liere et al., 2009). Furthermore, a number of functional genetic variants in several transporter genes are known (Bruhn and Cascorbi, 2014); however, their impact on neurosteroid transport is so far largely unknown. Variations in transporter function may affect concentrations and action of several neurosteroids in brain. Therefore, a better understanding of these processes is an important aspect also in the context of a possible therapeutic use of these compounds.

\section{AUTHOR CONTRIBUTIONS}

MG and GJ conceived and wrote the manuscript. PH designed Figure 1 and revised the manuscript. All authors read and approved the manuscript for publication.

\section{FUNDING}

The authors were supported by grants from the Bundesministerium für Bildung und Forschung (BMBF, 03IP612A) and from the Deutsche Forschungsgemeinschaft (DFG, JE 234/4-1).

Akwa, Y., Ladurelle, N., Covey, D. F., and Baulieu, E. E. (2001). The synthetic enantiomer of pregnenolone sulfate is very active on memory in rats and mice, even more so than its physiological neurosteroid counterpart: distinct mechanisms? Proc. Natl. Acad. Sci. U.S.A. 98, 14033-14037. doi: 10.1073/pnas. 241503698

Alebouyeh, M., Takeda, M., Onozato, M. L., Tojo, A., Noshiro, R., Hasannejad, H., et al. (2003). Expression of human organic anion transporters 
in the choroid plexus and their interactions with neurotransmitter metabolites. J. Pharmacol. Sci. 93, 430-436. doi: 10.1254/jphs.9 3.430

Arbo, B. D., Bennetti, F., and Ribeiro, M. F. (2016). Astrocytes as a target for neuroprotection: modulation by progesterone and dehydroepiandrosterone. Prog. Neurobiol. 144, 27-47. doi: 10.1016/j.pneurobio.2016.03.010

Aronica, E., Gorter, J. A., Redeker, S., van Vliet, E. A., Ramkema, M., Scheffer, G. L., et al. (2005). Localization of breast cancer resistance protein (BCRP) in microvessel endothelium of human control and epileptic brain. Epilepsia 46, 849-857. doi: 10.1111/j.1528-1167.2005.66604.x

Asaba, H., Hosoya, K., Takanaga, H., Ohtsuki, S., Tamura, E., Takizawa, T., and Terasaki, T. (2000). Blood-brain barrier is involved in the efflux transport of a neuroactive steroid, dehydroepiandrosterone sulfate, via organic anion transporting polypeptide 2. J. Neurochem. 75, 1907-1916. doi: 10.1046/j.14714159.2000.0751907.x

Ballatori, N., Christian, W. V., Wheeler, S. G., and Hammond, C. L. (2013). The heteromeric organic solute transporter, OSTalpha-OSTbeta/SLC51: a transporter for steroid-derived molecules. Mol. Aspects Med. 34, 683-692. doi: 10.1016/j.mam.2012.11.005

Baulieu, E. E. (1997). Neurosteroids: of the nervous system, by the nervous system, for the nervous system. Recent Prog. Horm. Res. 52, 1-32.

Belleville-Rolland, T., Sassi, Y., Decouture, B., Dreano, E., Hulot, J. S., Gaussem, P., et al. (2016). MRP4 (ABCC4) as a potential pharmacologic target for cardiovascular disease. Pharmacol. Res. 107, 381-389. doi: 10.1016/j.phrs.2016. 04.002

Bortfeld, M., Rius, M., Konig, J., Herold-Mende, C., Nies, A. T., and Keppler, D. (2006). Human multidrug resistance protein 8 (MRP8/ABCC11), an apical efflux pump for steroid sulfates, is an axonal protein of the CNS and peripheral nervous system. Neuroscience 137, 1247-1257. doi: 10.1016/j.neuroscience. 2005.10.025

Bronger, H., Konig, J., Kopplow, K., Steiner, H. H., Ahmadi, R., Herold-Mende, C., et al. (2005). ABCC drug efflux pumps and organic anion uptake transporters in human gliomas and the blood-tumor barrier. Cancer Res. 65, 11419-11428. doi: 10.1158/0008-5472.CAN-05-1271

Bruhn, O., and Cascorbi, I. (2014). Polymorphisms of the drug transporters $\mathrm{ABCB} 1, \mathrm{ABCG} 2, \mathrm{ABCC} 2$ and $\mathrm{ABCC} 3$ and their impact on drug bioavailability and clinical relevance. Expert Opin. Drug Metab. Toxicol. 10, 1337-1354. doi: 10.1517/17425255.2014.952630

Burckhardt, G. (2012). Drug transport by organic anion transporters (OATs). Pharmacol. Ther. 136, 106-130. doi: 10.1016/j.pharmthera.2012.0 7.010

Chaves, C., Shawahna, R., Jacob, A., Scherrmann, J. M., and Decleves, X. (2014). Human ABC transporters at blood-CNS interfaces as determinants of CNS drug penetration. Curr. Pharm. Des. 20, 1450-1462. doi: 10.2174/ 13816128113199990466

Chen, Z. S., Guo, Y., Belinsky, M. G., Kotova, E., and Kruh, G. D. (2005). Transport of bile acids, sulfated steroids, estradiol 17-beta-D-glucuronide, and leukotriene C4 by human multidrug resistance protein 8 (ABCC11). Mol. Pharmacol. 67, 545-557. doi: 10.1124/mol.104.007138

Chen, Z. S., Lee, K., and Kruh, G. D. (2001). Transport of cyclic nucleotides and estradiol 17-beta-D-glucuronide by multidrug resistance protein 4 . Resistance to 6-mercaptopurine and 6-thioguanine. J. Biol. Chem. 276, 33747-33754. doi: 10.1074/jbc.M104833200

Chisari, M., Eisenman, L. N., Covey, D. F., Mennerick, S., and Zorumski, C. F. (2010). The sticky issue of neurosteroids and GABA(A) receptors. Trends Neurosci. 33, 299-306. doi: 10.1016/j.tins.2010.03.005

Choudhuri, S., Cherrington, N. J., Li, N., and Klaassen, C. D. (2003). Constitutive expression of various xenobiotic and endobiotic transporter mRNAs in the choroid plexus of rats. Drug Metab. Dispos. 31, 1337-1345. doi: 10.1124/dmd. 31.11.1337

Cole, S. P., Bhardwaj, G., Gerlach, J. H., Mackie, J. E., Grant, C. E., Almquist, K. C., et al. (1992). Overexpression of a transporter gene in a multidrug-resistant human lung cancer cell line. Science 258, 1650-1654. doi: 10.1126/science. 1360704

Cooray, H. C., Blackmore, C. G., Maskell, L., and Barrand, M. A. (2002). Localisation of breast cancer resistance protein in microvessel endothelium of human brain. Neuroreport 13, 2059-2063. doi: 10.1097/00001756-20021115000014
Cropp, C. D., Komori, T., Shima, J. E., Urban, T. J., Yee, S. W., More, S. S., et al. (2008). Organic anion transporter 2 (SLC22A7) is a facilitative transporter of cGMP. Mol. Pharmacol. 73, 1151-1158. doi: 10.1124/mol.107.043117

Dallas, S., Miller, D. S., and Bendayan, R. (2006). Multidrug resistance-associated proteins: expression and function in the central nervous system. Pharmacol. Rev. 58, 140-161. doi: 10.1124/pr.58.2.3

de Peretti, E., and Mappus, E. (1983). Pattern of plasma pregnenolone sulfate levels in humans from birth to adulthood. J. Clin. Endocrinol. Metab. 57, 550-556. doi: 10.1210/jcem-57-3-550

Doyle, L. A., Yang, W., Abruzzo, L. V., Krogmann, T., Gao, Y., Rishi, A. K., et al. (1998). A multidrug resistance transporter from human MCF-7 breast cancer cells. Proc. Natl. Acad. Sci. U.S.A. 95, 15665-15670. doi: 10.1073/pnas.95.26. 15665

Fang, F., Christian, W. V., Gorman, S. G., Cui, M., Huang, J., Tieu, K., et al. (2010). Neurosteroid transport by the organic solute transporter OSTalpha-OSTbeta. J. Neurochem. 115, 220-233. doi: 10.1111/j.1471-4159.2010.06920.x

Gao, B., Hagenbuch, B., Kullak-Ublick, G. A., Benke, D., Aguzzi, A., and Meier, P. J. (2000). Organic anion-transporting polypeptides mediate transport of opioid peptides across blood-brain barrier. J. Pharmacol. Exp. Ther. 294, 73-79.

Gao, B., Vavricka, S. R., Meier, P. J., and Stieger, B. (2015). Differential cellular expression of organic anion transporting peptides OATP1A2 and OATP2B1 in the human retina and brain: implications for carrier-mediated transport of neuropeptides and neurosteriods in the CNS. Pflugers Arch. 467, 1481-1493. doi: 10.1007/s00424-014-1596-x

Gazzin, S., Strazielle, N., Schmitt, C., Fevre-Montange, M., Ostrow, J. D., Tiribelli, C., et al. (2008). Differential expression of the multidrug resistancerelated proteins $\mathrm{ABCb} 1$ and $\mathrm{ABCc} 1$ between blood-brain interfaces. J. Comp. Neurol. 510, 497-507. doi: 10.1002/cne.21808

Grube, M., Kock, K., Karner, S., Reuther, S., Ritter, C. A., Jedlitschky, G., et al. (2006). Modification of OATP2B1-Mediated transport by steroid hormones. Mol. Pharmacol. 70, 1735-1741. doi: 10.1124/mol.106.026450

Grube, M., Reuther, S., Meyer Zu Schwabedissen, H., Kock, K., Draber, K., et al. (2007). Organic anion transporting polypeptide $2 \mathrm{~B} 1$ and breast cancer resistance protein interact in the transepithelial transport of steroid sulfates in human placenta. Drug Metab. Dispos. 35, 30-35. doi: 10.1124/dmd.106.01 1411

Hagenbuch, B., and Stieger, B. (2013). The SLCO (former SLC21) superfamily of transporters. Mol. Aspects Med. 34, 396-412. doi: 10.1016/j.mam.2012. 10.009

Haimeur, A., Conseil, G., Deeley, R. G., and Cole, S. P. (2004). The MRP-related and BCRP/ABCG2 multidrug resistance proteins: biology, substrate specificity and regulation. Curr. Drug Metab. 5, 21-53. doi: 10.2174/13892000434 89199

Harteneck, C. (2013). Pregnenolone sulfate: from steroid metabolite to TRP channel ligand. Molecules 18, 12012-12028. doi: 10.3390/molecules 18101 2012

Hirrlinger, J., Konig, J., Keppler, D., Lindenau, J., Schulz, J. B., and Dringen, R. (2001). The multidrug resistance protein MRP1 mediates the release of glutathione disulfide from rat astrocytes during oxidative stress. J. Neurochem. 76, 627-636. doi: 10.1046/j.1471-4159.2001.00101.x

Hojo, Y., Higo, S., Kawato, S., Hatanaka, Y., Ooishi, Y., Murakami, G., et al. (2011). Hippocampal synthesis of sex steroids and corticosteroids: essential for modulation of synaptic plasticity. Front. Endocrinol. 2:43. doi: 10.3389/fendo. 2011.00043

Hoshi, Y., Uchida, Y., Tachikawa, M., Inoue, T., Ohtsuki, S., and Terasaki, T. (2013). Quantitative atlas of blood-brain barrier transporters, receptors, and tight junction proteins in rats and common marmoset. J. Pharm. Sci. 102, 3343-3355. doi: 10.1002/jps.23575

Huber, R. D., Gao, B., Sidler, P., fandler, M. A., Zhang-Fu, W., Leuthold, S., et al. (2007). Characterization of two splice variants of human organic anion transporting polypeptide 3A1 isolated from human brain. Am. J. Physiol. Cell Physiol. 292, C795-C806. doi: 10.1152/ajpcell.00597.2005

Huss, W. J., Gray, D. R., Greenberg, N. M., Mohler, J. L., and Smith, G. J. (2005). Breast cancer resistance protein-mediated efflux of androgen in putative benign and malignant prostate stem cells. Cancer Res. 65, 6640-6650. doi: 10.1158/ 0008-5472.CAN-04-2548

Imai, Y., Asada, S., Tsukahara, S., Ishikawa, E., Tsuruo, T., and Sugimoto, Y. (2003). Breast cancer resistance protein exports sulfated estrogens but 
not free estrogens. Mol. Pharmacol. 64, 610-618. doi: 10.1124/mol.64. 3.610

Ito, K., Uchida, Y., Ohtsuki, S., Aizawa, S., Kawakami, H., Katsukura, Y., et al. (2011). Quantitative membrane protein expression at the blood-brain barrier of adult and younger cynomolgus monkeys. J. Pharm. Sci. 100, 3939-3950. doi: $10.1002 / j p s .22487$

Jedlitschky, G., Greinacher, A., and Kroemer, H. K. (2012). Transporters in human platelets: physiologic function and impact for pharmacotherapy. Blood 119, 3394-3402. doi: 10.1182/blood-2011-09-336933

Jedlitschky, G., Leier, I., Buchholz, U., Barnouin, K., Kurz, G., and Keppler, D. (1996). Transport of glutathione, glucuronate, and sulfate conjugates by the MRP gene-encoded conjugate export pump. Cancer Res. 56, 988-994.

Ji, C., Tschantz, W. R., Pfeifer, N. D., Ullah, M., and Sadagopan, N. (2012). Development of a multiplex UPLC-MRM MS method for quantification of human membrane transport proteins OATP1B1, OATP1B3 and OATP2B1 in in vitro systems and tissues. Anal. Chim. Acta 717, 67-76. doi: 10.1016/j.aca. 2011.12.005

Kancheva, R., Hill, M., Novak, Z., Chrastina, J., Kancheva, L., and Starka, L. (2011). Neuroactive steroids in periphery and cerebrospinal fluid. Neuroscience 191, 22-27. doi: 10.1016/j.neuroscience.2011.05.054

Kancheva, R., Hill, M., Novak, Z., Chrastina, J., Velikova, M., Kancheva, L., et al. (2010). Peripheral neuroactive steroids may be as good as the steroids in the cerebrospinal fluid for the diagnostics of CNS disturbances. J. Steroid Biochem. Mol. Biol. 119, 35-44. doi: 10.1016/j.jsbmb.2009.12.006

Keppler, D. (2011). Multidrug resistance proteins (MRPs, ABCCs): importance for pathophysiology and drug therapy. Handb. Exp. Pharmacol. 201, 299-323. doi: 10.1007/978-3-642-14541-4_8

Kikuchi, R., Kusuhara, H., Sugiyama, D., and Sugiyama, Y. (2003). Contribution of organic anion transporter 3 (Slc22a8) to the elimination of p-aminohippuric acid and benzylpenicillin across the blood-brain barrier. J. Pharmacol. Exp. Ther. 306, 51-58. doi: 10.1124/jpet.103.049197

Kilic, E., Spudich, A., Kilic, U., Rentsch, K. M., Vig, R., Matter, C. M., et al. (2008). ABCC1: a gateway for pharmacological compounds to the ischaemic brain. Brain 131, 2679-2689. doi: 10.1093/brain/awn222

Koenen, A., Kock, K., Keiser, M., Siegmund, W., Kroemer, H. K., and Grube, M. (2012). Steroid hormones specifically modify the activity of organic anion transporting polypeptides. Eur. J. Pharm. Sci. 47, 774-780. doi: 10.1016/j.ejps. 2012.08.017

Kool, M., de Haas, M., Scheffer, G. L., Scheper, R. J., van Eijk, M. J., Juijn, J. A., et al. (1997). Analysis of expression of cMOAT (MRP2), MRP3, MRP4, and MRP5, homologues of the multidrug resistance-associated protein gene (MRP1), in human cancer cell lines. Cancer Res. 57, 3537-3547.

Kubo, Y., Ohtsuki, S., Uchida, Y., and Terasaki, T. (2015). Quantitative determination of luminal and abluminal membrane distributions of transporters in porcine brain capillaries by plasma membrane fractionation and quantitative targeted proteomics. J. Pharm. Sci. 104, 3060-3068. doi: $10.1002 /$ jps. 24398

Kullak-Ublick, G. A., Fisch, T., Oswald, M., Hagenbuch, B., Meier, P. J., Beuers, U., et al. (1998). Dehydroepiandrosterone sulfate (DHEAS): identification of a carrier protein in human liver and brain. FEBS Lett. 424, 173-176. doi: 10.1016/ S0014-5793(98)00168-9

Labrie, F., Belanger, A., Cusan, L., Gomez, J. L., and Candas, B. (1997). Marked decline in serum concentrations of adrenal C19 sex steroid precursors and conjugated androgen metabolites during aging. J. Clin. Endocrinol. Metab. 82, 2396-2402. doi: 10.1210/jcem.82.8.4160

Lee, W., Glaeser, H., Smith, L. H., Roberts, R. L., Moeckel, G. W., Gervasini, G., et al. (2005). Polymorphisms in human organic anion-transporting polypeptide 1A2 (OATP1A2): implications for altered drug disposition and central nervous system drug entry. J. Biol. Chem. 280, 9610-9617. doi: 10.1074/jbc.M41109 2200

Leggas, M., Adachi, M., Scheffer, G. L., Sun, D., Wielinga, P., Du, G., et al. (2004). Mrp4 confers resistance to topotecan and protects the brain from chemotherapy. Mol. Cell. Biol. 24, 7612-7621. doi: 10.1128/MCB.24.17.76127621.2004

Liere, P., Pianos, A., Eychenne, B., Cambourg, A., Bodin, K., Griffiths, W., et al. (2009). Analysis of pregnenolone and dehydroepiandrosterone in rodent brain: cholesterol autoxidation is the key. J. Lipid Res. 50, 2430-2444. doi: 10.1194/jlr. M900162-JLR200
Liu, S., Sjovall, J., and Griffiths, W. J. (2003). Neurosteroids in rat brain: extraction, isolation, and analysis by nanoscale liquid chromatography-electrospray mass spectrometry. Anal. Chem. 75, 5835-5846. doi: 10.1021/ac0346297

Loe, D. W., Almquist, K. C., Deeley, R. G., and Cole, S. P. (1996). Multidrug resistance protein (MRP)-mediated transport of leukotriene C4 and chemotherapeutic agents in membrane vesicles. Demonstration of glutathionedependent vincristine transport. J. Biol. Chem. 271, 9675-9682. doi: 10.1074/ jbc.271.16.9675

Lopez-Nieto, C. E., You, G., Bush, K. T., Barros, E. J., Beier, D. R., and Nigam, S. K. (1997). Molecular cloning and characterization of NKT, a gene product related to the organic cation transporter family that is almost exclusively expressed in the kidney. J. Biol. Chem. 272, 6471-6478. doi: 10.1074/jbc.272.10. 6471

Maninger, N., Wolkowitz, O. M., Reus, V. I., Epel, E. S., and Mellon, S. H. (2009). Neurobiological and neuropsychiatric effects of dehydroepiandrosterone (DHEA) and DHEA sulfate (DHEAS). Front. Neuroendocrinol. 30, 65-91. doi: 10.1016/j.yfrne.2008.11.002

Miller, D. S., Nobmann, S. N., Gutmann, H., Toeroek, M., Drewe, J., and Fricker, G. (2000). Xenobiotic transport across isolated brain microvessels studied by confocal microscopy. Mol. Pharmacol. 58, 1357-1367. doi: 10.1124/mol.58.6. 1357

Miyajima, M., Kusuhara, H., Fujishima, M., Adachi, Y., and Sugiyama, Y. (2011). Organic anion transporter 3 mediates the efflux transport of an amphipathic organic anion, dehydroepiandrosterone sulfate, across the blood-brain barrier in mice. Drug Metab. Dispos. 39, 814-819. doi: 10.1124/dmd.110.036863

Miyake, K., Mickley, L., Litman, T., Zhan, Z., Robey, R., Cristensen, B., et al. (1999). Molecular cloning of cDNAs which are highly overexpressed in mitoxantroneresistant cells: demonstration of homology to $\mathrm{ABC}$ transport genes. Cancer Res. $59,8-13$.

Monnet, F. P., Mahe, V., Robel, P., and Baulieu, E. E. (1995). Neurosteroids, via sigma receptors, modulate the $[3 \mathrm{H}]$ norepinephrine release evoked by N-methyl-D-aspartate in the rat hippocampus. Proc. Natl. Acad. Sci. U.S.A. 92, 3774-3778. doi: 10.1073/pnas.92.9.3774

Mori, S., Takanaga, H., Ohtsuki, S., Deguchi, T., Kang, Y. S., Hosoya, K., et al. (2003). Rat organic anion transporter 3 (rOAT3) is responsible for brain-toblood efflux of homovanillic acid at the abluminal membrane of brain capillary endothelial cells. J. Cereb. Blood Flow Metab. 23, 432-440. doi: 10.1097/01.WCB. 0000050062.57184 .75

Niehof, M., and Borlak, J. (2009). Expression of HNF4alpha in the human and rat choroid plexus: implications for drug transport across the blood-cerebrospinalfluid (CSF) barrier. BMC Mol. Biol. 10:68. doi: 10.1186/1471-219910-68

Nies, A. T., Jedlitschky, G., Konig, J., Herold-Mende, C., Steiner, H. H., Schmitt, H. P., et al. (2004). Expression and immunolocalization of the multidrug resistance proteins, MRP1-MRP6 (ABCC1-ABCC6), in human brain. Neuroscience 129, 349-360. doi: 10.1016/j.neuroscience.2004.07.051

Nishimura, M., and Naito, S. (2005). Tissue-specific mRNA expression profiles of human ATP-binding cassette and solute carrier transporter superfamilies. Drug Metab. Pharmacokinet. 20, 452-477. doi: 10.2133/dmpk.20.452

Nishizawa, K., Nakanishi, T., and Tamai, I. (2017). Comparative evaluation of dehydroepiandrosterone sulfate potential to predict hepatic organic anion transporting polypeptide transporter-based drug-drug interactions. Drug Metab. Dispos. 45, 224-227. doi: 10.1124/dmd.116.072355

Pizzagalli, F., Hagenbuch, B., Stieger, B., Klenk, U., Folkers, G., and Meier, P. J. (2002). Identification of a novel human organic anion transporting polypeptide as a high affinity thyroxine transporter. Mol. Endocrinol. 16, 2283-2296. doi: 10.1210/me.2001-0309

Pizzagalli, F., Varga, Z., Huber, R. D., Folkers, G., Meier, P. J., and St Pierre, M. V. (2003). Identification of steroid sulfate transport processes in the human mammary gland. J. Clin. Endocrinol. Metab. 88, 3902-3912. doi: 10.1210/jc. 2003-030174

Porcu, P., Barron, A. M., Frye, C. A., Walf, A. A., Yang, S. Y., He, X. Y., et al. (2016). Neurosteroidogenesis today: novel targets for neuroactive steroid synthesis and action and their relevance for translational research. J. Neuroendocrinol. 28:12351. doi: 10.1111/jne.12351

Qian, Y. M., Song, W. C., Cui, H., Cole, S. P., and Deeley, R. G. (2001). Glutathione stimulates sulfated estrogen transport by multidrug resistance protein 1. J. Biol. Chem. 276, 6404-6411. doi: 10.1074/jbc.M008251200 
Rao, V. V., Dahlheimer, J. L., Bardgett, M. E., Snyder, A. Z., Finch, R. A., Sartorelli, A. C., et al. (1999). Choroid plexus epithelial expression of MDR1 $\mathrm{P}$ glycoprotein and multidrug resistance-associated protein contribute to the blood-cerebrospinal-fluid drug-permeability barrier. Proc. Natl. Acad. Sci. U.S.A. 96, 3900-3905. doi: 10.1073/pnas. 96.7 .3900

Reddy, D. S. (2010). Neurosteroids: endogenous role in the human brain and therapeutic potentials. Prog. Brain Res. 18, 113-137. doi: 10.1016/B978-0-44453630-3.00008-7

Ritter, C. A., Jedlitschky, G., Meyer Zu Schwabedissen, H., Grube, M., Kock, K., and Kroemer, H. K. (2005). Cellular export of drugs and signaling molecules by the ATP-binding cassette transporters MRP4 (ABCC4) and MRP5 (ABCC5). Drug Metab. Rev. 37, 253-278. doi: 10.1081/DMR-200047984

Roberts, L. M., Black, D. S., Raman, C., Woodford, K., Zhou, M., Haggerty, J. E., et al. (2008a). Subcellular localization of transporters along the rat bloodbrain barrier and blood-cerebral-spinal fluid barrier by in vivo biotinylation. Neuroscience 155, 423-438. doi: 10.1016/j.neuroscience.2008.06.015

Roberts, L. M., Woodford, K., Zhou, M., Black, D. S., Haggerty, J. E., Tate, E. H., et al. (2008b). Expression of the thyroid hormone transporters monocarboxylate transporter-8 (SLC16A2) and organic ion transporter14 (SLCO1C1) at the blood-brain barrier. Endocrinology 149, 6251-6261. doi: 10.1210/en.2008-0378

Salman, E. D., Faye-Petersen, O., and Falany, C. N. (2011). Hydroxysteroid sulfotransferase $2 \mathrm{~B} 1 \mathrm{~b}$ expression and localization in normal human brain. Horm. Mol. Biol. Clin. Investig. 8, 445-454. doi: 10.1515/HMBCI.2011.117

Sanchez-Guijo, A., Oji, V., Hartmann, M. F., Traupe, H., and Wudy, S. A. (2015). Simultaneous quantification of cholesterol sulfate, androgen sulfates, and progestagen sulfates in human serum by LC-MS/MS. J. Lipid Res. 56, 1843-1851. doi: 10.1194/jlr.D061499

Seljeset, S., Laverty, D., and Smart, T. G. (2015). Inhibitory neurosteroids and the GABAA receptor. Adv. Pharmacol. 72, 165-187. doi: 10.1016/bs.apha.2014.1 0.006

Shawahna, R., Uchida, Y., Decleves, X., Ohtsuki, S., Yousif, S., Dauchy, S., et al. (2011). Transcriptomic and quantitative proteomic analysis of transporters and drug metabolizing enzymes in freshly isolated human brain microvessels. Mol. Pharm. 8, 1332-1341. doi: 10.1021/mp200129p

Spiegl-Kreinecker, S., Buchroithner, J., Elbling, L., Steiner, E., Wurm, G., Bodenteich, A., et al. (2002). Expression and functional activity of the ABCtransporter proteins P-glycoprotein and multidrug-resistance protein 1 in human brain tumor cells and astrocytes. J. Neurooncol. 57, 27-36. doi: 10.1023/ A:1015735815111

St Pierre, M. V., Hagenbuch, B., Ugele, B., Meier, P. J., and Stallmach, T. (2002). Characterization of an organic anion-transporting polypeptide (OATP-B) in human placenta. J. Clin. Endocrinol. Metab. 87, 1856-1863. doi: 10.1210/jcem. 87.4.8431

Suzuki, M., Suzuki, H., Sugimoto, Y., and Sugiyama, Y. (2003). ABCG2 transports sulfated conjugates of steroids and xenobiotics. J. Biol. Chem. 278, 22644-22649. doi: 10.1074/jbc.M212399200

Tamai, I., Nezu, J., Uchino, H., Sai, Y., Oku, A., Shimane, M., et al. (2000). Molecular identification and characterization of novel members of the human organic anion transporter (OATP) family. Biochem. Biophys. Res. Commun. 273, 251-260. doi: 10.1006/bbrc.2000.2922
Uchida, Y., Ohtsuki, S., Katsukura, Y., Ikeda, C., Suzuki, T., Kamiie, J., et al. (2011). Quantitative targeted absolute proteomics of human blood-brain barrier transporters and receptors. J. Neurochem. 117, 333-345. doi: 10.1111/ j.1471-4159.2011.07208.x

Uchida, Y., Zhang, Z., Tachikawa, M., and Terasaki, T. (2015). Quantitative targeted absolute proteomics of rat blood-cerebrospinal fluid barrier transporters: comparison with a human specimen. J. Neurochem. 134, 1104-1115. doi: 10.1111/jnc.13147

Wang, D. Y., and Bulbrook, R. D. (1969). The binding of steroids to plasma proteins in normal women and women with breast cancer. Eur. J. Cancer 5, 247-253. doi: 10.1016/0014-2964(69)90074-7

Warren, M. S., Zerangue, N., Woodford, K., Roberts, L. M., Tate, E. H., Feng, B., et al. (2009). Comparative gene expression profiles of ABC transporters in brain microvessel endothelial cells and brain in five species including human. Pharmacol. Res. 59, 404-413. doi: 10.1016/j.phrs.2009.02.007

Watanabe, M., Watanabe, T., Yabuki, M., and Tamai, I. (2015). Dehydroepiandrosterone sulfate, a useful endogenous probe for evaluation of drug-drug interaction on hepatic organic anion transporting polypeptide (OATP) in cynomolgus monkeys. Drug Metab. Pharmacokinet. 30, 198-204. doi: 10.1016/j.dmpk.2014.12.009

Weill-Engerer, S., David, J. P., Sazdovitch, V., Liere, P., Eychenne, B., Pianos, A., et al. (2002). Neurosteroid quantification in human brain regions: comparison between Alzheimer's and nondemented patients. J. Clin. Endocrinol. Metab. 87, 5138-5143. doi: 10.1210/jc.2002-020878

Wijnholds, J., deLange, E. C., Scheffer, G. L., van den Berg, D. J., Mol, C. A., van, D. V, et al. (2000). Multidrug resistance protein 1 protects the choroid plexus epithelium and contributes to the blood-cerebrospinal fluid barrier. J. Clin. Invest. 105, 279-285. doi: 10.1172/JCI8267

Wu, F. S., Gibbs, T. T., and Farb, D. H. (1991). Pregnenolone sulfate: a positive allosteric modulator at the N-methyl-D-aspartate receptor. Mol. Pharmacol. 40, 333-336.

Zelcer, N., Reid, G., Wielinga, P., Kuil, A., van, D. H. I., Schuetz, J. D., et al. (2003). Steroid and bile acid conjugates are substrates of human multidrug-resistance protein (MRP) 4 (ATP-binding cassette C4). Biochem. J. 371, 361-367. doi: 10.1042/bj20021886

Zhang, Y., Schuetz, J. D., Elmquist, W. F., and Miller, D. W. (2004). Plasma membrane localization of multidrug resistance-associated protein homologs in brain capillary endothelial cells. J. Pharmacol. Exp. Ther. 311, 449-455. doi: $10.1124 /$ jpet.104.068528

Conflict of Interest Statement: The authors declare that the research was conducted in the absence of any commercial or financial relationships that could be construed as a potential conflict of interest.

Copyright (c) 2018 Grube, Hagen and Jedlitschky. This is an open-access article distributed under the terms of the Creative Commons Attribution License (CC BY). The use, distribution or reproduction in other forums is permitted, provided the original author(s) and the copyright owner are credited and that the original publication in this journal is cited, in accordance with accepted academic practice. No use, distribution or reproduction is permitted which does not comply with these terms. 